\title{
Uma proposta de formação docente no contexto da utilização das tecnologias da informação e comunicação no curso de Pedagogia da FaE/CBH/UEMG: linhas e entrelinhas
}

\author{
Santuza Abras ${ }^{1}$ \\ santuzaa@gmail.com \\ Cleder Tadeu Antão da Silva ${ }^{2}$ \\ tadeuuemg@gmail.com \\ Luciana Zenha ${ }^{3}$ \\ luciana.zenha@gmail.com \\ Alecir Carvalho \\ alecircarvalho@gmail.com
}

\begin{abstract}
Resumo
O presente artigo analisa a experiência da Faculdade de Educação da UEMG de Belo Horizonte na implantação de uma proposta de formação de professores e gestores da educação básica, no contexto da inclusão do debate sobre a utilização das Tecnologias da Informação e Comunicação em seu
\end{abstract}

1 Mestre em Educação Tecnológica pelo Centro Federal de Educação Tecnológica de Minas Gerais (CEFET-MG), professora, pesquisadora, e vice-reitora da Universidade do Estado de Minas Gerais. 2 Mestre em Educação Tecnológica pelo CEFET-MG, professor, pesquisador e coordenador do Núcleo de Estudos e Pesquisas em Educação, Comunicação e Tecnologia (NECT) da FaE/CBH/UEMG.

3 Doutoranda em Educação pela Universidade Federal de Minas Gerais (UFMG), professora e pesquisadora da FaE/CBH/ UEMG.

4 Mestre em Design pela Escola de Design da UEMG, professor, pesquisador e sub coordenador do Núcleo de Estudos e Pesquisas em Educação, Comunicação e Tecnologia (NECT) da FaE/CBH/UEMG. 
curso de Pedagogia. Nesse sentido, são discutidas as ações desenvolvidas pela instituição nos campos do ensino, pesquisa e extensão, em que se destacam os processos de reformulação curricular, a aquisição de infraestrutura tecnológica e a criação de um núcleo de estudos e pesquisas que se notabilizou por ser o ponto culminante do desenvolvimento de uma política efetiva para as áreas de Educação, Comunicação e Tecnologia na faculdade.

Palavras-Chave: Pedagogia; formação docente; TIC.

\section{Introdução}

O presente artigo trata da experiência da Faculdade de Educação da Universidade do Estado de Minas Gerais, campus Belo Horizonte (FaE/CBH/UEMG), na implantação de uma proposta de formação de professores e gestores da educação básica, no contexto da inclusão do debate sobre a utilização das Tecnologias da Informação e Comunicação (TICs), em seu curso de Pedagogia.

O texto, que busca resgatar o histórico da política de educação e tecnologia da faculdade, traz os antecedentes da proposta, passando pelas ações realizadas pela instituição, no que se refere à inserção dessa discussão no referido curso de Pedagogia da FaE/CBH/UEMG, onde se descrevem também as diferentes iniciativas que se constituíram em práticas pedagógicas de formação para seus estudantes, servidores e educadores.

Promove-se ainda, de forma paralela, uma reflexão sobre os desafios que esse campo da educação e tecnologia apresenta para a formação de docentes da educação básica no atual contexto, delineando ainda algumas possíveis perspectivas que contribuam para o avanço dessa área nos próximos anos no País.

\section{A Pedagogia e as novas demandas de formação}

Atualmente, a Pedagogia tem sido alvo de grandes discussões em relação à sua área de estudo. Nesse aspecto, o debate epistemológico que permeia seu campo por vezes é colocado em xeque, em que se questiona a 
sua identidade, a sua legitimidade e até mesmo o seu papel na sociedade contemporânea, apesar de em outros momentos este saber ser afirmado como um tipo de conhecimento específico que contempla peculiaridades e especificidades, como discute (ROCHA, 2001):

De fato, se por um lado a Pedagogia é destituída de autonomia por aqueles que consideram a impossibilidade de se estatuir um conhecimento científico de base prática, por outro, temos assistido a uma construção da Pedagogia como forma de consolidar seu estatuto e dar conta de uma demanda concreta de organização das práticas e das experiências educativas humanas, mas que é essencialmente diferente delas (ROCHA, 2001, p. 28).

Para Libâneo (2002), a Pedagogia

[...] ocupa-se das práticas educativas intencionais destinadas a favorecer o desenvolvimento dos indivíduos no interior de sua cultura por meio de processos de transmissão e assimilação ativa de experiências, saberes e modos de ação culturalmente organizados.

[...] situa-se entre as ciências que dão o suporte teórico a essas vias de acesso (sociologia, filosofia etc.), entretanto distingue-se delas por ter a tarefa de integrar os enfoques parciais do fenômeno educativo para analisá-lo em sua globalidade (LIBÂNEO, 2002, p. 162).

Tal cenário tem despertado nos pedagogos e nos formadores de professores uma busca permanente de reflexão, com especial preocupação para os desafios que estão postos para a Pedagogia no atual contexto da contemporaneidade. Tais desafios têm gerado, sobretudo, uma tentativa de se pensar em propostas de formação nessa área que estabeleça um diálogo estreito entre tais proposições e às necessidades e demandas emergentes encontradas.

Entre as diversas demandas que a Pedagogia tem se dedicado a debater no atual contexto, encontra-se o campo da Educação e Tecnologia, que apresenta avanços significativos nos últimos anos, seja através do desenvolvimento de políticas públicas de inclusão digital ou das próprias 
iniciativas de formação de professores para o uso das TICs nos diversos níveis de ensino.

Prova disso é que, desde as últimas décadas, parte da literatura educacional tem se dedicado a desenvolver importantes discussões sobre a temática das inovações tecnológicas. Perrenoud (2000), por exemplo, já afirmava que as TICs têm transformado os modos de trabalhar, pensar e comunicar, e que a partir daí é necessário realizar uma reflexão crítica em relação à sua utilização, assim como de avaliar suas implicações para os processos de aprendizagem, como se observa no trecho a seguir:

Uma cultura tecnológica de base também é necessária para pensar as relações entre a evolução dos instrumentos (informática e hipermídia), as competências intelectuais e a relação com o saber que a escola pretende formar. Pelo menos sob esse ângulo, as tecnologias novas não poderiam ser indiferentes a nenhum professor, por modificarem as maneiras de viver, de se divertir, de se informar, de trabalhar e de pensar. Tal evolução afeta, portanto, as situações que os alunos enfrentam e enfrentarão, nas quais eles pretensamente mobilizam e mobilizarão o que aprenderam na escola (PERRENOUD, 2000, p. 138).

Já Moran (2000), ao discutir as mudanças na educação envolvendo transformações nos processos de comunicação por meio da utilização de novas mídias e outras tecnologias, afirmara que a educação é um ato de mediação, uma ação que facilita o processo de aprendizagem dos alunos pessoal e profissionalmente para cidadania:

Os processos de comunicação tendem a ser mais participativos. A relação professor-aluno mais aberta, interativa. Haverá uma integração maior entre as tecnologias e das metodologias de trabalhar o oral, a escrita e o audiovisual.

Ensinar com novas mídias será uma revolução, se mudamos simultaneamente os paradigmas convencionais do ensino, que mantêm distantes professores e alunos. Caso contrário conseguiremos dar um verniz de modernidade, sem mexer no essencial (MORAN, 2000, p. 7). 
O avanço das TICs e o desenvolvimento de seu processo de apropriação pelos sujeitos têm produzido novas interlocuções para a área tecnológica. Kerkhove (2009), em suas discussões sobre psicotecnologia, ${ }^{5}$ demonstra que a experiência acumulada pelos indivíduos a partir do contato com os novos meios técnicos promove uma verdadeira mutação na consciência humana, especialmente em termos de sua extensão:

Com a videoconferência e os videofones, a televisão aproxima-se da flexibilidade e da comunicação instantânea conseguida com o telefone. De fato, estas tecnologias não apenas prolongam as propriedades de envio e recepção da consciência, como penetram e modificam a consciência dos seus utilizadores. A realidade virtual ainda está mais ajustada a nós. Acrescenta o tato à visão e à audição e está mais próxima de revestir totalmente o sistema nervoso humano do que qualquer tecnologia até hoje o fez. Com a realidade virtual e a telepresença permitida pela robótica projetamos literalmente para o exterior a nossa consciência e vemo-la "objetivamente". Esta é a primeira vez que o homem consegue fazer isso (KERKHOVE, 2009, p. 23-24).

Nessa direção, Behar et al. (2009) defendem que os impactos produzidos pelas transformações geradas através das TICs promovem mudanças significativas também no universo das práticas pedagógicas. O crescimento da produção de objetos de aprendizagem tem exigido cada vez mais uma adaptação por parte dos professores, no que diz respeito a sua própria atuação, no qual o docente abandona o papel de transmissor do conhecimento e assume um papel de medição nos processos educativos.

A utilização de objetos de aprendizagem remete a um novo tipo de aprendizagem, apoiada pela tecnologia, na qual o professor abandona o papel de transmissor de informação para desempenhar um papel de mediador da aprendizagem. Logo, cada vez mais recursos didáticos para uso no computador vem sendo desenvolvidos e publicados para serem agregados ao processo de aprendizagem,

5 Psicotecnologia é um termo cunhado por Kerkhove para definir qualquer tecnologia que emula, estende ou amplifica o poder de nossas mentes. 
adaptando-os às diferentes necessidades, tais como de público, conteúdo, tempo e prática pedagógica (BEHAR, et al., 2009, p. 66).

Nesse sentido, Silva e Garíglio (2010), ao analisarem as políticas públicas de uso das TICs nas escolas, destacam a importância de se preparar adequadamente o profissional da educação nessa área, considerando que o trabalho com essas tecnologias na educação dependem fundamentalmente de uma boa formação docente para o sucesso dos programas:

Diante de tal contexto, torna-se essencial destacar, portanto, a importância da formação de professores para o uso das TIC nas escolas: políticas de qualificação voltadas para esses profissionais são estratégias indispensáveis ao projeto de inclusão digital, visto a não formulação de ações nessa direção poder fazer com que as políticas de inclusão digital corram o risco de ficar apenas na dimensão do discursivo político formal, mantendo-se distante da realidade prática das escolas brasileiras (SILVA; GARÍGLIO, 2010, p. 484).

Portanto, evidencia-se de forma cada vez mais clara, que a qualificação no campo da educação e tecnologia tem sido uma das demandas importantes para a Pedagogia nesses últimos anos. O fato dessas TICs se fazerem cada vez mais presentes nos diversos setores da sociedade, inclusive no campo educacional, faz com que elas se tornem uma condição sine qua non para cursos de formação de professores, tanto no âmbito da formação inicial, quanto nos programas de formação continuada.

\section{A tecnologia na FaE/CBH/UEMG: breve histórico}

Considerando a importância de se estabelecer um diálogo com esse novo panorama, pelo qual a Pedagogia vem se deparando, no ano de 1997, iniciam-se, na FaE/CBH/UEMG, as primeiras discussões coletivas para a reformulação do currículo de licenciatura plena em Pedagogia. Naquele momento, percebeu-se pouco interesse de parte dos educadores da faculdade em introduzir questões que envolviam o debate sobre a 
utilização das TICs na educação. Por se interessar por essa temática, a professora Santuza Abras objetou que, ao reformular tal currículo, que pretendia formar professores e gestores educacionais, seria inadmissível, ou melhor, imprescindível contemplar o debate acerca das implicações e potencialidades pedagógicas do uso das TICs nas práticas de ensino-aprendizagem nos diferentes níveis de ensino.

Antes mesmo desse desafio de reformulação do currículo do curso de Pedagogia da FaE/CBH/UEMG, a preocupação com a formação de professores, inclusive na área da educação e tecnologia, em especial no campo da informática, já existia no País, como evidencia Valente (1999):

[...] a formação de professores na área de informática na educação vem acontecendo desde 1983, quando foram iniciadas as primeiras experiências de uso do computador nessa área. Essa formação tem sido baseada em diversas abordagens que foram utilizadas ao longo desses quinze anos e que apresentam características distintas, ditadas pela necessidade de formação de profissionais qualificados, pelas limitações técnicas e financeiras, pelo nível de conhecimento que os pesquisadores dispõem e pelo interesse desses pesquisadores em elaborar e estudar novas metodologias de formação (VALENTE, 1999, p. 99).

Diante dessa realidade, é necessário contextualizar que naquela época não existia computadores, ambientes informatizados ou outras tecnologias da informação e comunicação destinadas a promover a formação de estudantes e educadores do curso de Pedagogia da Faculdade de Educação da UEMG de Belo Horizonte.

Entretanto, um levantamento realizado por Abras (1999), ${ }^{6}$ na forma de pesquisa exploratória com alunos de $5^{\circ}, 6^{\circ}$ e $7^{\circ}$ períodos de Pedagogia, visando a investigar as percepções que os estudantes apresentavam acerca da tecnologia, revelou um quadro bastante interessante e surpreendente sobre a representação que os futuros educadores tinham sobre essa temática.

Movidos pela hipótese de que haveria um número significativo de

6 Mestranda em Tecnologia do CEFET-MG, na área de concentração em Educação Tecnológica, no ano de 1995 - com publicação da dissertação em 1999. 
graduandos que teria resistência ao uso da tecnologia, os pesquisadores tinham como objetivo obter informações sobre o que esses estudantes pensavam sobre a questão do avanço tecnológico. As questões do questionário se dividiam em solicitar ao respondente que opinasse a respeito de:

a) seu conceito de tecnologia;

b) se os conceitos de ciência e tecnologia eram sinônimos;

c) se a tecnologia era boa ou má;

d) se o(a) entrevistado(a) era favorável ao avanço tecnológico e o que pensava sobre o mesmo;

e) como ele(a) imaginava o mundo daqui a dez anos, ou seja, em 2005;

f) que posição tomaria a educação nessa perspectiva de avanço;

g) se o(a) estudante trabalhava em alguma escola e em caso afirmativo, em que Rede de Ensino;

h) e finalmente, se o(a) entrevistado(a) gostaria de acrescentar outras informações e percepções.

Tal questionário foi intitulado "TECNOFILIA - TECNOFOBIA: um estudo exploratório com alunos da Faculdade de Educação da Universidade do Estado de Minas Gerais - curso de Pedagogia". Naquele momento histórico, os pesquisadores desejavam investigar se existiriam mais tecnófobos ou tecnofílicos entre os discentes entrevistados.

Cabe ressaltar que os conceitos de tecnofilia e tecnofobia são baseados nos termos utilizados por Papert (2008) quando este autor faz referência aos grupos de yearners e schoolers, que, segundo ele, são grupos de educadores que se encontram nas escolas e que se posicionam de maneira distinta quando defrontados com a perspectiva de inovação, inclusive em relação à inserção de tecnologias que buscam promover transformações no dia a dia da escola. Encontra-se na obra do próprio autor este importante esclarecimento:

Oneologismo yearner origina-se do verbo inglês yearn - desejar fortemente algo difícil de tornar realidade, como a ânsia de liberdade por pessoas que vivem em um regime autoritário. E o neologismo (schoolers), 
uma forma verbal infinitiva do substantivo school (Escola) [...] significa aproximadamente "defensores da instituição escolar na sua estrutura atual" (PAPERT, 2008, p. 17).

Nesse sentido, os yeaners, pela sua ânsia de romper com o status quo da escola, aproximam-se dos tecnofílicos, que são integrados à perspectiva de uso das tecnologias, já os schoolers, pela sua posição de manutenção da estrutura tradicional da escola, identificam-se com os tecnófobos, que veem na tecnologia uma ameaça, no que se refere a sua presença e utilização pela instituição escolar (PAPERT, 2008).

Feito esse esclarecimento, ressalta-se que no levantamento realizado por Abras (1999) analisou-se um conjunto de cem questionários, sem separação por turno ou turma.

Sobre a similaridade entre ciência e tecnologia, 24 alunos(as) afirmaram que sim, existe similaridade entre os termos, 68 responderam que não, e oito não expressaram opinião. Interessante notar que 88 alunos(as) responderam que a tecnologia é um artefato bom, e um justificando-se pelo medo do novo, respondeu que a tecnologia é um artefato mau em si mesmo, sendo que outras 11 alunos(as) afirmaram que não é bom, nem mau, pois depende da forma como é utilizado. Já sobre a questão do avanço tecnológico, dos cem questionários aplicados, 97 foram favoráveis a esse avanço, sendo um contra e dois não se manifestaram.

As conclusões preliminares dão conta que 97\% dos(as) alunos(as) pesquisados eram favoráveis ao avanço tecnológico e que $88 \%$ desses estudantes consideravam a tecnologia como algo bom, em que foi possível identificar que eram poucos os discentes que apresentavam características tecnofóbicas. Esses dados, de certa forma, surpreenderam os pesquisadores e, ao mesmo tempo, mostraram boas perspectivas de aceitação dos(as) alunos(as) em relação às possíveis reformulações do currículo de Pedagogia, apontando assim para um perfil de formação que contemplasse aspectos relativos à área tecnológica.

Dentro dessa perspectiva, Moran (2007) afirma que:

Se os alunos fazem pontes entre o que aprendem intelectualmente e as situações reais, experimentais, profissionais ligadas aos seus estudos, a aprendizagem 
será mais significativa, viva, enriquecedora. As universidades e os professores precisam organizar nos seus currículos e cursos atividades integradoras da prática com a teoria, do compreender com o vivenciar, o fazer e o refletir, de forma sistemática, presencial e virtualmente, em todas as áreas e ao longo de todo o curso (MORAN, 2007, p. 6).

Portanto, educação e escola não poderiam ficar à margem desse debate, pois ficar aquém do acesso à tecnologia e de seus avanços significaria continuar subordinado às relações de poder que permeiam os interesses do sistema.

[...] Os países de primeiro mundo concentram-se na produção de bens com uso de intensivo de tecnologia e informação, como a indústria dos processadores de computador, redes ou telefonia, enquanto os países de terceiro mundo têm que se contentar com os produtos agrícolas, que têm baixíssimo valor agregado. Aos países em desenvolvimento como o Brasil é reservada parte da indústria, geralmente poluente, que aos países desenvolvidos não interessa mais manter em seus territórios. Nessa dinâmica produtiva, a capacidade de determinados países entrarem soberanamente no mercado global é cada vez mais remota. Conseqüentemente, o desemprego estrutural ou o subemprego tornam-se parte do cotidiano das nações periféricas (BRITO, 2001, p. 14).

Numa rota oposta a esse cenário, a educação precisaria se posicionar no sentido de promover intervenções que enfrentassem a reprodução dessas desigualdades, de maneira a favorecer práticas de inclusão social em busca de uma apropriação efetiva das TICs:

[...] a Escola se configura como um importante instrumento de inclusão social, no sentido da formação e instrumentalização para uma sociedade que exige o desenvolvimento de capacidades para um mercado de trabalho "informacional", mas, sobretudo, como fomentadora de contradição e espaço de formação da criticidade, tão fundamentais às transformações sociais. Como alicerces da "Sociedade da Informação", a Internet e 
o computador são ferramentas; e, como tais, podem ser utilizados para edificar uma sociedade sem excluídos (BRITO, 2001, p. 14).

Considerando essas contribuições, em seguida serão apresentadas as etapas do processo de inserção da temática das tecnologias na $\mathrm{FaE} / \mathrm{CBH} /$ UEMG, destacando a criação da infraestrutura técnica que possibilitou a construção de uma política mais ampla nesta área para a faculdade. Nesse percurso, analisam-se também as ações realizadas pela instituição, nos campos do ensino, da pesquisa, e da extensão e que foram os alicerces para a consolidação dessa proposta de formação de educadores.

\section{A proposta de formação docente da $\mathrm{FaE} / \mathrm{CBH} /$ UEMG no contexto das Tecnologias da Informação e Comunicação}

\subsection{Pesquisa e reforma curricular}

Como se destacou, a partir da reformulação do currículo de Pedagogia da FaE/CBH/UEMG em 1997, vários e intensos debates foram promovidos nos sentido de se planejar uma proposta de formação do pedagogo que contemplasse também o campo da educação e tecnologia.

Com isso, travou-se uma disputa para que na nova proposta curricular do curso pudesse conter um ciclo de formação optativo em Informática na Educação, mesmo que esse fosse oferecido após a conclusão do ciclo básico de quatro anos. Esse ciclo optativo, a ser realizado no nono semestre letivo, teria a carga de 500 horas-aula, acrescidas de mais cem horas de Práticas Pedagógicas de Formação.

Contudo, em se tratando de uma proposta de formação de docentes e pedagogos, seria necessário algo mais, pois, para Valente (1993):

[...] a formação do professor para ser capaz de integrar a informática nas atividades que realiza em sala de aula, deve prover condições para ele construir conhecimento sobre as técnicas computacionais, entender por que e como integrar o computador na sua prática pedagógica e ser capaz de superar barreiras de ordem administrativa e 
pedagógica. Essa prática possibilita a transição de um sistema fragmentado de ensino para uma abordagem integradora de conteúdo e voltada para a resolução de problemas específicos do interesse de cada aluno. Finalmente, deve-se criar condições para que o professor saiba recontextualizar o aprendizado e a experiência vividas durante a sua formação para a sua realidade de sala de aula, compatibilizando as necessidades de seus alunos e os objetivos pedagógicos que se dispõe a atingir (VALENTE, 1993, p. 22).

No entanto, a implantação do Currículo em 1998 foi feita sem conter disciplinas específicas relacionadas à educação e tecnologia nos ciclos de formação básica de caráter obrigatório. O currículo de Pedagogia da $\mathrm{FaE} / \mathrm{CBH} / \mathrm{UEMG}$ apresentava "Habilitações integradas relacionadas à docência para a Educação Básica - anos iniciais do Ensino Fundamental e gestão de processos educativos: administração, planejamento, inspeção, supervisão e orientação educacional".

Paralelamente às discussões do currículo, foi criado, em 16 de março de 1998, o grupo de pesquisa TEIA-GEPE ${ }^{7}$, sob a coordenação da professora Maria Inês de Matos Coelho.

O grupo TEIA-GEPE desenvolveu conhecimento acerca de processos de introdução de novas tecnologias na educação e na formação de professores. Realizou-se de agosto de 2001 a abril de 2003, o Projeto FAPEMIG SHA 1044/98 Introdução de Novas Tecnologias de Comunicação e Informação na educação o presencial e a distância: contextos, fatores e resultados. Também investigamos a relação entre compreensão e apropriação de espaços sociais da Internet e a prática em processos de formação de Professores na Universidade inclusive com desenvolvimento de ambiente virtual de formação docente em comunidade de prática, com apoio do $\mathrm{CNPq}$ (ago/2001 a dez/2003). No período de 1998 a fev de 2001, foram desenvolvidos com apoio do CNPq (maio de 1999 a março de 2001) dois projetos: I) A introdução de novas tecnologias de informação

7 Grupo de Estudos e Pesquisas de Tecnologias Interativas de Aprendizagem. 
e de comunicação na escola, os contextos, as mudanças no papel do professor, percepções, resistências, prática pedagógica e a capacitação dos professores; II) Ambientes interativos de aprendizagem e trabalho por WWW: fatores de avaliação e de design. Promovemos também o Projeto III) BH2 - Rede de alta velocidade(Consórcio PROTEM - CNPq-RNP) Capacitação de docentes de ensino superior na relação entre ensino, pesquisa e avaliação via Internet. (Apoio do $\mathrm{CNPq}, \mathrm{RNP}$ ). A pesquisa se integra com o ensino de graduação e com o ensino médio e fundamental. Outra repercussão é a capacitação de docentes pesquisadores. Além disto, promove divulgação e difusão científica, como Seminário de Educação e tecnologias de informação e de comunicação (COELHO, 2002, p. 1).

O TEIA-GEPE desenvolveu pesquisas com apoio do CNPq e FAPEMIG entre os anos de 1998 e 2003 e fez parte do Diretório de Grupos de Pesquisa do $\mathrm{CNPq}^{8}$. Ao longo das pesquisas realizadas pelo grupo, foram produzidos vários artigos, e uma das conclusões que um deles revela é que

A formação dos professores nas escolas precisa ser repensada no sentido de se tornar realmente inicial e continuada, como dois momentos distintos, e de contribuir para formas mais participativas de inserção da informática e de outras tecnologias de comunicação e de informação na escola. Para isto é preciso que os fatores organizacionais tanto do currículo escolar quanto do trabalho docente sejam alterados significativamente de forma a possibilitar o trabalho coletivo/ colaborativo entre professores e alunos e a integração curricular pela interdisciplinaridade.

8 O TEIA-GEPE desenvolveu vários projetos dentro do programa "Introdução de novas tecnologias de comunicação e informação na educação presencial e a distância". O Projeto 01 se referia à introdução de novas tecnologias de informação e comunicação na escola, os contextos, as mudanças no papel do professor, percepções, resistências, prática pedagógica e a capacitação de professores. O Projeto 02 tratava de ambientes interativos de aprendizagem trabalhando na perspectiva do WWW, assim como envolvia fatores de avaliação e design como continuidade do projeto "Gestão de C \& T" de 1997. Já o Projeto 03 era voltado à capacitação de docentes de ensino superior na relação entre ensino, pesquisa e avaliação via Internet. O projeto integrou o consórcio PROTEM-CNPqRNP - Projeto BH-2 - Rede Metropolitana de Alta Velocidade de BH. Atividade de ensino a distância. 
Uma estratégia-chave é manter um foco central nas trocas (on-line ou off-line) centradas no aprendiz e em profissionais que examinam resultados e trabalhos dos estudantes. O dar e receber entre estudantes, professores e profissionais ajuda aos participantes compreenderem suas próprias estratégias de pensamento e o contexto de outras (COELHO et al., 2001, p. 96).

Diante de tais constatações, depreende-se que:

O uso de tecnologia pode evoluir para ampliar as redes colaborativas de profissionais da educação, possibilitando o envolvimento deles em planejamento de desenvolvimento profissional com profissionais da tecnologia, construindo as habilidades, conhecimentos e compreensão profunda do conteúdo e da pedagogia requeridos para ensino e aprendizagem efetivo de estudantes e de outros educadores (COELHO et al., 2001, p. 97).

Paralelo ao TEIA-GEPE e dando sequência às ações voltadas para a implantação de estudos sobre educação e tecnologia na $\mathrm{FaE} / \mathrm{CBH} /$ UEMG, foi-se constituindo, a partir do segundo semestre de 1999, ainda de maneira muito tímida, um grupo de estudos para discutir as implicações do uso de TIC na educação em seus diversos níveis e espaços, grupo este coordenado pela professora Luciana Zenha Cordeiro9. O grupo que era composto por alunos de diversos Núcleos Formativos ${ }^{10}$, interessava-se em aprofundar seus conhecimentos e estudos sobre a temática tecnológica, sobretudo, devido à necessidade de buscar embasamento teórico para desenvolvimento de seus trabalhos de conclusão de curso.

A necessidade de tais encontros era imperiosa visto que à época havia no curso de Pedagogia da FaE/CBH/UEMG uma carência de professores habilitados para orientar tais trabalhos. Os encontros aconteciam aos sábados à tarde, num trabalho voluntário da professora, já que a faculdade não dispunha ainda de espaços ou laboratórios de informática

9 Professora da FaE/CBH/UEMG e naquele período mestranda em Educação e Novas Linguagens pela UFMG.

10 Os Núcleos Formativos no curso de Pedagogia da FaE/CBH/UEMG ainda hoje correspondem aos períodos semestrais de formação. 
e a dinâmica dos encontros baseava-se em leituras, discussões de textos, relatos de experiências e, eventualmente de algumas experimentações, a partir do uso de um notebook disponibilizado pela própria professora.

A partir do aprofundamento das discussões e estudos realizados pelo grupo, tornava-se urgente a adoção de políticas para a implantação e implementação de laboratórios, a aquisição de bibliografia específica e a criação de outras iniciativas que pudessem consolidar uma proposta de utilização e análise das implicações das TIC na educação.

De certa forma, concretizava-se, assim, a preocupação já evidenciada nos embates de reestruturação curricular do curso de Pedagogia da FaE/ $\mathrm{CBH} / \mathrm{UEMG}$, em que era cada vez mais notório que a área de educação e tecnologia não poderia ser um apêndice no rol das disciplinas optativas do curso, mas precisaria se tornar uma realidade, compondo os ciclos básicos de formação do pedagogo, como já alertava Cysneiros (1991):

A informatização da escola também deve começar pelas Faculdades de Educação. É importante que o pedagogo e o licenciado de qualquer disciplina se familiarizem com o computador desde o início de sua formação profissional (CYSNEIROS, 1991, p. 48).

Nesse sentido, a Faculdade de Educação da UEMG estava ciente que era necessário partir para uma ação pontual, no sentido de contribuir efetivamente para a formação do pedagogo, visando a preparar esse profissional para enfrentar os novos desafios e perspectivas que envolviam o processo de disseminação e apropriação das tecnologias no âmbito das práticas educativas e mais, que tais ações deveriam ser ampliadas para além do universo das pesquisas acadêmicas.

\subsection{O fortalecimento da política de educação e tecnologia da FaE/CBH/UEMG: a criação do NECT e a consolidação de sua infraestrutura tecnológica}

A partir de meados do ano 2000, o Grupo de Estudos em Educação e Tecnologia, orientado pela professora Luciana Zenha, reunir-se-ia com os então candidatos à direção e vice-direção da instituição, respectivamente, os professores José Cosme Drumond e Santuza Abras ${ }^{11}$, para discutir 
propostas e reivindicar políticas para a área de Educação e Tecnologia da FaE/CBH/UEMG. Era ponto pacífico que seria necessário criar um espaço multiuso para que alunos e professores pudessem vivenciar as novas formas de comunicação, a partir da experiência de utilização das tecnologias da informação em interseção com as práticas educativas. Seria necessário também, intensificar as reflexões advindas desse campo de conhecimento, de forma a estabelecer uma política concreta na área tecnológica para a comunidade acadêmica da faculdade.

Naquele momento, foi acordado com os professores supracitados que não seriam poupados esforços para que fossem tomadas medidas efetivas para criação desse espaço, que em princípio seria um laboratório de informática, com perspectiva de ampliação de utilização de outras mídias. No entanto, reivindicava-se também que fossem inseridos disciplinas nos currículos dos cursos de graduação e pós-graduação da instituição, para atendimento às necessidades da comunidade, tanto sob o ponto de vista da formação de educadores, quanto em relação às demandas acadêmicas de discentes e docentes.

A partir daí, iniciaram-se os levantamentos necessários para orientar a implantação desse espaço multiuso, etapa inicial para implementação de um projeto para uso das TICs na educação, como enfatiza Tajra (2001):

Para implantar ou reformular um projeto de informática educativa, podemos optar por uma metodologia a partir dos seguintes passos: diagnóstico tecnológico da escola, do professor e do aluno; plano de ação; capacitação dos docentes; conhecimento e pesquisa de softwares; elaboração do projeto pedagógico com uso de informática educativa; implantação e avaliação do projeto e replanejamento (TAJRA, 2001, p. 84).

Ao pensar na inserção dos computadores em ambientes educacionais muitos fatores são analisados, tais como: quantos computadores precisam instalar? Qual é a configuração dos computadores? Os computadores? Os

11 Os professores José Cosme Drumond e Santuza Abras foram responsáveis pela direção da Faculdade de Educação da UEMG entre os anos de 2000 e 2004. 
computadores ficarão em rede? Qual rede deverá ser utilizada? É necessário que todos os computadores possuam kits multimídia? Devemos colocar a Internet em todos os computadores? Qual tipo de conexão de acesso à Internet estaremos utilizando? Quais softwares serão comprados? Esses softwares são multiusuários? Ou monousuários? Quem será o coordenador das atividades do ambiente de informática? Quais são as suas funções? (TAJRA, 2001, p. 98).

Essa etapa foi importante para que, a partir do segundo semestre de 2000, com a posse da nova direção da FaE/CBH/UEMG, medidas fossem tomadas para a criação do primeiro laboratório de informática da instituição, como iniciativa principal de estabelecimento de uma política na área de Educação e Tecnologia. O Laboratório de Informática da FaE/CBH/UEMG se constituiu num espaço dedicado à discussão e realização de experiências na área de Educação e Tecnologia e fora inaugurado em setembro de 2001. Sua implementação contou com o auxílio de uma equipe de designers ${ }^{12}$, que desenvolveu uma proposta de layout que pudesse proporcionar ao ambiente aspectos de mobilidade e flexibilidade durante os procedimentos de uso dos computadores, apresentando um caráter bastante inovador para a época. O mobiliário do laboratório se organizava em círculos, em que as mesas eram móveis e a organização de cabeamento fora planejado para permitir possíveis adequações. Os conceitos de mobilidade e autossustentação, além de modernos, encaixavam-se dentro de uma perspectiva inclusiva ${ }^{13}$, já que todos os computadores foram instalados com o Sistema Operacional Linux ${ }^{14}$.

12 Os designers Alecir Carvalho, Fernando Lima e Welison Capeletti desenvolveram um projeto de mobiliário com características de mobilidade e flexibilidade de forma a atender a demanda da instituição.

13 A implantação foi planejada para que alunos e professores se adaptassem ao modelo e a uma versão menos popular de uso de interface - o software livre. Esse processo de implantação não foi fácil, uma vez que a maioria dos usuários já utilizavam o Sistema Operacional Windows e muitos rejeitavam reaprender ou compreender a nova lógica de acesso à informação.

14 Sistema Operacional baseado em licença GPL, em que é permitido que o usuário utilize, estude, modifique e distribua o software de acordo com princípios livres. 


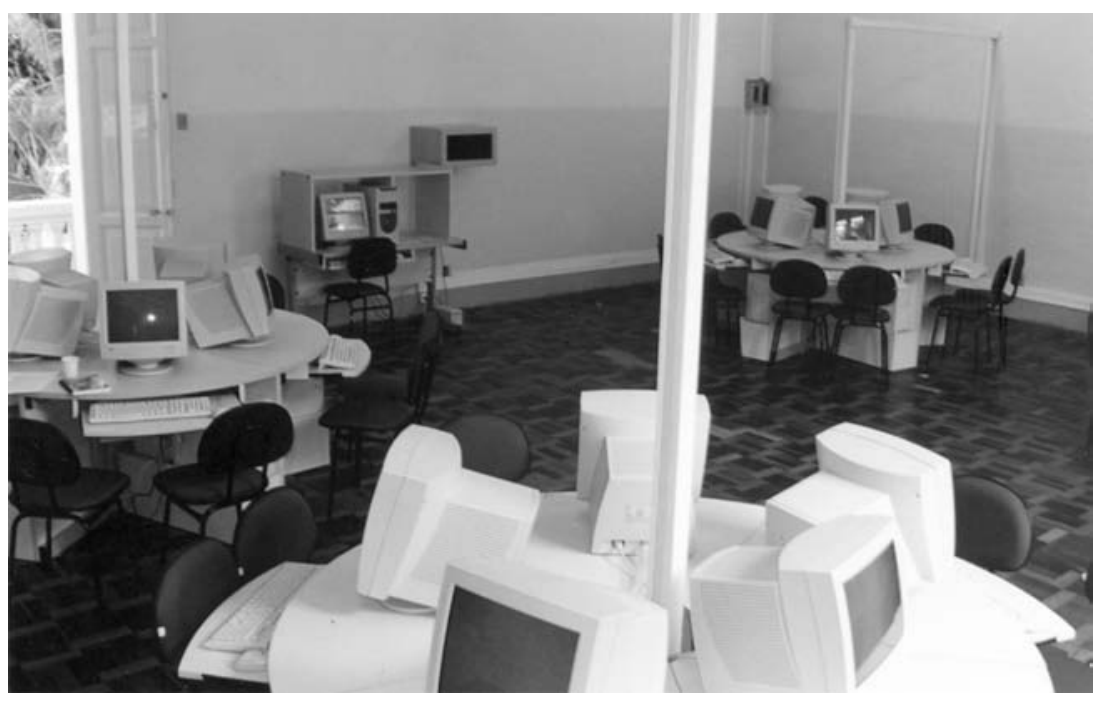

FIGURA 1 - Laboratório de informática da FaE/CBH/UEMG inaugurado em setembro de 2001

Fonte: Centro de Comunicação FAE/CBH/UEMG, 2001.

Tal espaço constituiu-se, então, no embrião para a criação do Núcleo de Estudos e Pesquisas em Educação, Comunicação e Tecnologia (NECT), que tinha como objetivo coordenar e implantar uma política tanto em termos teóricos quanto práticos na área Tecnológica para a FaE/CBH/UEMG. Sob a coordenação dos professores Daniel Mill e Haroldo Bertoldo ${ }^{15}$ e a participação de vários professores da instituição, com formação em diversas áreas do conhecimento, o NECT deu início às suas atividades, atuando no desenvolvimento de múltiplos projetos nas áreas de ensino, pesquisa e extensão.

A partir de 2002, finalmente foram criadas disciplinas que seriam incluídas no currículo do curso de Pedagogia, proposta essa que contou com a participação dos professores do núcleo e representantes da direção e coordenação de curso. Com o título de "Estudos sobre Educação,

15 O professor-doutor Daniel Mill participou de todo o processo de criação e expansão do NECT até 2006, sendo responsável pela formação de grupos de estudos, realização de pesquisas e estabelecimento de parcerias com outros núcleos. O professor-mestre Haroldo Bertoldo esteve vinculado ao NECT até 2009 e foi responsável pela expansão do laboratório de produção de mídias, além de desenvolver outros projetos de pesquisa e extensão. 
Comunicação e Tecnologia", as disciplinas foram alocadas nos Núcleos Formativos 2, 5, 6 e 7, integrados a outras temas-disciplinas já existentes no currículo de Pedagogia.

No QUADRO 1, seguem as disciplinas incorporadas ao currículo do curso de Pedagogia com suas respectivas ênfases:

\section{Quadro 01}

Relação de disciplinas incorporadas pelo currículo de

Pedagogia da FaE/CBH/UEMG

\begin{tabular}{|c|c|c|}
\hline Disciplina & Ementa & \begin{tabular}{|c|c} 
Núcleo \\
Formativo \\
\end{tabular} \\
\hline $\begin{array}{l}\text { Sociedade da } \\
\text { Informação }\end{array}$ & $\begin{array}{l}\text { Analisa do ponto de vista das teorias da sociedade } \\
\text { da informação (pós industrial ou pós moderna), do } \\
\text { fenômeno informacional na estrutura e organização } \\
\text { da sociedade contemporânea, assim como na } \\
\text { constituição e distribuição da cultura/educação. }\end{array}$ & II \\
\hline $\begin{array}{l}\text { Mediação } \\
\text { Pedagógica }\end{array}$ & $\begin{array}{l}\text { Introdução e desenvolvimento de projetos que } \\
\text { perpassem o ensino/aprendizagem como um todo } \\
\text { em uma perspectiva interacionista: epistemologias } \\
\text { subjacentes ao trabalho docente, com ênfase numa } \\
\text { didática baseada nas estruturas da inteligência e no } \\
\text { meio sócio-cultural. O enfoque dado está relacionado } \\
\text { a recursos e tecnologias de informação e comunicação } \\
\text { - TICS (Tecnologias de Informação e Comunicação). }\end{array}$ & $\mathrm{V}$ \\
\hline $\begin{array}{l}\text { Softwares } \\
\text { Educativos }\end{array}$ & $\begin{array}{l}\text { Descreve e analisa a produção tecnológica no campo } \\
\text { da informática aplicada à educação, em termos } \\
\text { de aplicativos dirigidos ao processo de ensino- } \\
\text { aprendizagem, enfocando as construções de novos } \\
\text { ambientes de aprendizagem e sua repercussão no } \\
\text { âmbito educativo. }\end{array}$ & VI \\
\hline $\begin{array}{l}\text { Mídias e } \\
\text { EAD }\end{array}$ & $\begin{array}{l}\text { Analisa o desenvolvimento dos meios de comunicação } \\
\text { eletrônicos e das redes digitais e sua influência na } \\
\text { práxis educativa e na atual sociedade da informação, } \\
\text { enfocando também a construção de ambientes } \\
\text { de aprendizagem cooperativos, fazendo uso das } \\
\text { tecnologias no processo ensino/aprendizagem. }\end{array}$ & VII \\
\hline
\end{tabular}

Fonte: Dossiê NECT, 2002. 
Portanto, além de promover uma formação teórica e prática por meio de sua estrutura curricular básica, o NECT também começou a desenvolver outros projetos, atuando na promoção de cursos e oficinas de informática básica abertos à comunidade acadêmica e atuando também no oferecimento de tópicos de enriquecimento curricular direcionados aos estudantes de graduação da faculdade. O núcleo também iniciou sua participação na proposta de extensão universitária “Universidade Livre - pleno viver", ${ }^{16}$ projeto que visava a incluir pessoas da terceira idade em processos de iniciação a informática.

O Núcleo de Estudos e Pesquisas em Educação, Comunicação e Tecnologia também promoveu diversas ações de qualificação para a utilização das TICs, entre elas destacam-se o curso Normal Superior da FaE/CBH/UEMG, em parceria com a Prefeitura Municipal de Betim, e o curso Normal Superior a distância, desenvolvido em parceria com a Secretaria de Estado da Educação de Minas Gerais, denominado “Projeto Veredas". Cabe ressaltar que o NECT também contribui com a formação de servidores da UEMG oferecendo minicursos de inclusão digital para funcionários e professores e realizando diversos treinamentos específicos para gestores, bibliotecários e secretários acadêmicos. ${ }^{17}$

A partir do ano 2003, o NECT cria seu curso de Pós-Graduação lato sensu em "Educação, Comunicação e Tecnologia", com as ênfases em mídias e educação, "Educação a Distância e Práticas Presenciais em Informática Educativa”, destinado a formar profissionais e educadores, especificamente nesse campo de conhecimento.

Entre as ações que contemplam as políticas da FaE/CBH/UEMG na área de educação e tecnologia pode-se citar ainda a proposta de criação e implantação do Centro de Estudos e Pesquisas em Educação a Distância (CEPEAD), projeto que foi desenvolvido pela Faculdade de Educação em conjunto com o Núcleo de Educação a Distância da Universidade (NEAD/UEMG).

Atualmente, o NECT e o CEPEAD vêm desenvolvendo pesquisas,

16 O projeto "Universidade Livre - pleno viver" foi um curso de extensão voltado para a inclusão digital de alunos da melhor idade e coordenado pela Pró-Reitoria de Pesquisa e Extensão da UEMG. 17 Os projetos realizados no NECT nesse período contaram com supervisão do núcleo e com a coordenação dos professores Cleder Tadeu Silva, Carlos Helmar Duarte e Sirléia Ferreira Rosa. 
projetos de extensão e outras propostas de intervenção voltadas ao desenvolvimento do trabalho pedagógico utilizando as TICs, tanto no âmbito presencial quanto na modalidade a distância. Podem ser citadas as pesquisas e propostas extensionistas sobre "Plataformas Open Source, Acessibilidade e Softwares de Inclusão para pessoas com Deficiência", "Projeto Regênesis de Formação Continuada de Professores", "Produção e uso de Objetos de Aprendizagem na Escola", entre outros.

\section{Considerações finais}

As tecnologias são decorrentes de toda a transformação histórica. É preciso compreender os movimentos complexos nos quais as sociedades têm se defrontado, especialmente nos benefícios e prejuízos causados pela interação homem-máquina. Independente dos dispositivos móveis digitais utilizados neste momento, inclusive na sala de aula, sejam eles notebooks, tablets, telas, teclados, celulares, entre outros, o mais importante é a constante busca pelo acesso à informação, pela produção de um conhecimento pessoal, processual, consistente e que privilegie a construção coletiva de uma aprendizagem significativa.

Um dos grandes desafios da atualidade, portanto, é contextualizar e pensar formas de desenvolver ações que perpassem o cotidiano da educação e das tecnologias. Kenski (2007, p. 127) afirma que "na nova realidade, o tempo da educação é o tempo da vida". A autora reafirma ser necessário que políticas educacionais e instituições educativas estejam alinhadas pelas novas exigências.

Nessa mesma perspectiva, Filatro (2004) afirma que educação para toda vida passa a ser uma exigência permanente de toda a sociedade, desembocando na compreensão da escola e da Universidade como conceito e não como lócus. "[...] A educação tradicional vê aflorar novas formas de pensar, de construir e de comunicar com o conhecimento, as quais lançam importantes questionamentos quanto a seus objetivos, práticas e resultados" (FILATRO, 2004, p. 36). Filatro ainda complementa que precisamos compreender alguns elementos básicos das TICs não apenas de forma técnica, mas os significados para as atividades humanas. 
É nesse sentido que as tecnologias da informação e comunicação podem ser incorporadas no cotidiano das escolas e de todos envolvidos com a educação e a cidadania.

Por esse motivo, é que se torna um grande desafio para as universidades e para os professores formadores pensar na formação de agentes incentivadores e multiplicadores de mudança nos mais variados níveis da Educação Básica. Espera-se, de maneira audaciosa e ousada, contribuir para a apropriação das tecnologias digitais nas escolas, colaborando com a formação de pedagogos que critiquem, estudem, dominem e se apropriem das tecnologias como um recurso didático inovador (TAPSCOTT, 2010).

A experiência da Faculdade de Educação da UEMG de Belo Horizonte, de certa forma, traduz esse desejo já expresso nas contribuições dos diversos autores, como Tapscott (2010), Filatro (2004), Kenski (2007), entre tantos outros, de se pensar a inserção das TICs nas práticas educativas das escolas e universidades, no sentido de promover mudanças que possam colaborar com a melhoria das intervenções pedagógicas.

É somente a partir da construção de ações coletivas em direção ao processo de aquisição de práticas de inclusão e letramento digital, que será possível sair do plano das possibilidades vislumbradas em direção à utilização concreta desses valiosos recursos, de forma que se avance concretamente para se estabelecer um novo patamar de qualidade para o ensino e a aprendizagem de nossas instituições educativas. 


\section{Referências}

ABRAS, S. Interlocução pedagógica com professoras de ciências da terceira série do ensino fundamental: efeitos de uma prática revisitada. 180f. Dissertação (Mestrado em Tecnologia) - CEFET-MG, Belo Horizonte, 1999.

BEHAR, P. A. et al. Modelos pedagógicos em educação a distância. Porto Alegre: Artmed, 2009.

BRITO, V. P. Sociedade da informação e educação. Sociedade da Informação e Educação, Belo Horizonte, p. 06-21, dez. 2001.

COELHO, M. I. M. Introdução de Novas Tecnologias de Comunicação e Informação na educação o presencial e a distância: contextos, fatores e resultados. Boletim Informativo - Grupo de Estudos e Pesquisas de Tecnologias Interativas de Aprendizagem - TEIA-GEPE, Belo Horizonte, 2002.

et al. A introdução de novas tecnologias de informação e de comunicação na escola: um estudo exploratório - o caso do ProInfoMG, Belo Horizonte. Educação em Foco, Belo Horizonte, n. 22, p. 14-28, 2001.

CYSNEIROS, P. G. Aspectos sociológicos da informática educativa. Tecnologia Educacional, Rio de Janeiro, v. 20, n. 102/103, p. 45-48, set./ dez. 1991.

FILATRO, A. Design instrucional contextualizado: Educação e Tecnologia. São Paulo: Editora SENAC, 2004.

KENSKI, V. M. Educação e Tecnologias: o novo ritmo da informação. Campinas: Papirus, 2007. 
KERKHOVE, D. A pele da cultura: investigando a nova realidade eletrônica. São Paulo: Annablume, 2009.

LIBÂNEO, J. C. Pedagogia e Pedagogos, para quê? 6. ed. São Paulo: Cortez Editora, 2002.

MORAN, J. M. Informática na Educação: teoria \& prática. Porto Alegre, v. 3, n. 1. UFRGS. Programa de Pós-Graduação em Informática na Educação, p. 137-144, 2000.

; A educação que desejamos: novos desafios e como chegar lá. 2. ed. Campinas: Papirus, 2007.

; MASETTO, M.; BEHRENS, M. Novas tecnologias e mediação pedagógica. 13. ed. São Paulo: Papirus, 2009.

. Aprendizagem significativa. São Paulo: Entrevista ao Portal Escola Conectada, Instituto Ayrton Senna, 2008. Disponível em: http:/ / www.eca.usp.br/prof/moran/significativa.htm. Acesso em: 11 nov. 2011.

PAPERT, S. A máquina das crianças: repensando a escola na era da informática. Porto Alegre: Artmed, 2008.

PERRENOUD, P. Dez novas competências para ensinar. Porto Alegre: Editora Artmed, 2000.

ROCHA, E. A. C. A pedagogia e a educação infantil. Revista Brasileira de Educação, Rio de Janeiro, n. 16, p. 27-34, jan./abr. 2001.

SILVA, C. T. A.; GARÍGLIO, J. A. A formação continuada de professores para o uso das Tecnologias da Informação e Comunicação (TIC): o caso do projeto Escolas em Rede da Rede Estadual de Educação de Minas Gerais. Revista Diálogo Educacional, Curitiba, PUC/ 
PR, v. 10, n. 31, set./dez. 2010.

TJARA, S. F. Informática na educação: novas ferramentas pedagógicas para o professor da atualidade. 3. ed. São Paulo: Érika, 2001.

TAPSCOTT, D. A hora da Geração Digital: como jovens que cresceram usando a internet estão mudando tudo, das empresas aos governos. Rio de Janeiro: Agir Negócios, 2010.

VALENTE, José A. (Org.) Computadores e conhecimento: repensando a educação. Campinas, SP: Gráfica Central da UNICAMP, 1993

- O computador na sociedade do conhecimento: Brasília: Ministério da Educação, 1999. (Coleção informática para a mudança na educação). 


\title{
A proposal for teacher education in the context of the use of information technology and communication in the faculty of Pedagogy of the FaE/CBH/UEMG: lines and lines
}

\begin{abstract}
The present article analyzes the experience of Faculdade de Educação of UEMG in Belo Horizonte in implementing a proposal of formation of professors and basic education managers, in the context of the inclusion of the debate about the use of Tecnologies of Information and Communication in the Education course. To this end, the actions developed by the institution in the education, research and extension fields are discussed, where are emphasized the processes of curricular reformulation, the acquisition of technological infrastructure and the creation of a study and research core that excelled itself for being the high point of the development of an effective policy for areas of Education, Technology and Communication in the university.
\end{abstract}

Keywords: Pedagogy; teacher training; TIC.

Recebido: 08/11/11

Aprovado: 16/12/11 